УДК $544.77,542.06$

\title{
УСЛОВИЯ СОВМЕСТНОГО УДАЛЕНИЯ СОЕДИНЕНИЙ КРЕМНИЯ И ГУМИНОВЫХ ВЕЩЕСТВ ИЗ ПРИРОДНЫХ ВОД В ПРИСУТСТВИИ ПРОДУКТОВ ТЕРМИЧЕСКОЙ ОБРАБОТКИ МАГНЕЗИТА
}

\author{
Костикова Лариса Анатольевна', \\ lak@tpu.ru \\ Шиян Людмила Николаевна', \\ shln@tpu.ru
}

Мачехина Ксения Игоревна',

mauthksu@yandex.ru

\author{
Коршунов Андрей Владимирович', \\ korshunov@tpu.ru
' Национальный исследовательский Томский политехнический университет, Россия, 634050, г. Томск, пр. Ленина, 30.

\begin{abstract}
Актуальность. Подземные воды Западно-Сибирского региона характеризуются повышенным содержанием ионов железа, силикат ионов и органических веществ гумусового происхождения. Эти примеси способствуют образованию устойчивой коллоидной системы. При использовании природной воды в качестве теплоносителя на поверхности труб формируются силикатные отложения за счет связывания катионов кальция, магния, алюминия, железа. Совместное присутствие силикатов и органических примесей приводит к снижению эффективности очистки воды с применением существующих технологий водоподготовки.

Цель: определение концентрационных и температурных условий образования соединений кремния с гуминовыми веществами и скорости их осаждения в присутствии продуктов термической обработки магнезита (каустического магнезита).

объекты: природные воды и модельные растворы, содержащие соединения кремния и растворенные гуминовые вещества, каустический магнезит.

Методы: фотоколориметрия, рН-метрия, титриметрия, атомно-эмиссионная спектрометрия с индуктивно связанной плазмой (ICAP-6000).

Результаты. Установлен интервал массовых соотношений растворимых гуминовых веществ и силикатов ГВ: $\mathrm{SiO}_{3}{ }^{2-}=0,8-4$, в котором гуминовые вещества и $\mathrm{SiO}_{3}{ }^{2-}$-ионы при совместном присутствии в интервале $\mathrm{pH}=5 . .9$ связываются в органо-минеральные комплексы. В природных высокоцветных водах (содержание органических веществ до 30 мгО/л) до 40 \% силикат ионов может быть связано в такие комплексы. Размер образующихся коллоидных частиц составил порядка 200 нм, значение $\zeta$-потенциала составило -38 mV. При использовании каустического магнезита в качестве реагента-осадителя взаимодействие в системе "силикат-гуминовые вещества» протекает в две стадии, определяющие технологическую целесообразность одновременного удаления из воды силикатов и гуминовых веществ.
\end{abstract}

\section{Ключевые слова:}

Природные воды, соединения кремния, органо-минеральные комплексы, размер частиц, очистка воды, каустический магнезит.

\section{Введение}

Подземные воды Западной Сибири характеризуются содержанием ионов железа, силикат-ионов и органических веществ гумусового происхождения. Соединения железа и кремния попадают в воду в результате растворения минералов [1], а заболоченность территории способствует обогащению подземных вод гуминовыми веществами. Содержание силикат-ионов в подземных водах варьируется от 10 до 30 мг/л, при нормативном значении 10,0 мг/л [2]. Наличие в воде водорастворимых соединений кремния оказывает негативное влияние по следующим причинам.

Во-первых, избыток силикатов в питьевой воде отрицательно влияет на здоровье людей, провоцируя атеросклеротические процессы в органах и кровеносных сосудах, что влечет за собой инсульты, инфаркты, гипертоническую болезнь и, в конечном итоге, сокращает продолжительность жизни населения северных районов Западной Сибири [3].
Во-вторых, присутствие силикатов серьезно осложняет работу теплоснабжающих предприятий из-за образования в водогрейных трубах силикатной накипи, которая резко снижает тепловую производительность котлов и, как следствие, увеличивает расход топлива котельных. Удаление силикатной накипи по сравнению с очисткой от накипи из солей жесткости дорогой и сложный процесс, вплоть до замены труб, пораженных силикатной накипью [4].

Проблемы, связанные с присутствием силикатов в воде, обусловлены тем, что в настоящее время не существует четкого представления о механизме образования водорастворимых соединений кремния, присутствующих в поверхностных и скважинных водах, что является основным препятствием для нахождения простых и эффективных способов его удаления. Отсутствие знаний о путях образования водорастворимых соединений кремния не позволяет понять структуру этих соедине- 
ний и представить их молекулярное строение и, соответственно, их свойства, что осложняет поиск и разработку эффективных способов воздействия.

Одним из способов воздействия, согласно литературным данным [5-10], является изменение $\mathrm{pH}$ раствора, приводящее к диссоциации соединений кремния, влияние становится заметным лишь при $\mathrm{pH}>8$, а присутствие в воде ионов кальция и магния приводит к образованию малорастворимых силикатов, что снижает содержание соединений кремния в растворе. Поэтому основными реагентами для удаления силикат-ионов являются гашеная известь и магнезит, которые, взаимодействуя с кремниевой кислотой, образуют нерастворимые силикаты кальция и магния, соответственно.

Практика показывает, что введение в воду каустического магнезита с температурой до $40{ }^{\circ} \mathrm{C}$ в количестве 10-15 мг на 1 мг $\mathrm{H}_{2} \mathrm{SiO}_{3}$ позволяет снизить содержание примесей кремния в растворе до $1-1,5$ мг/л. При повышении температуры процесс удаления примесей силикат-ионов протекает более интенсивно. Так, при температуре $96{ }^{\circ} \mathrm{C}$ остаточное содержание силикат-ионов составляет всего лишь $0,25 \mathrm{мг/л} \mathrm{[11].}$

В литературе нет данных по удалению силикатионов в присутствии других компонентов раствоpa, с которыми он может взаимодействовать в водной среде, например, с гуминовыми веществами.

Цель настоящей работы заключалась в определении концентрационных и температурных условий образования органо-минеральных комплексов силикатов с гуминовыми веществами и их осаждения в присутствии продуктов термической обработки магнезита.

\section{Материалы и методы исследования}

В работе рассматривали природные подземные воды Томской области и модельные растворы, содержащие силикат и гумат натрия в концентрациях, близких по содержанию силикат-ионов и растворенных гуминовых веществ к природным водам. Модельные растворы с $\mathrm{pH}=7,2 . . .7,5$ готовили по методике, предложенной в $[12,13]$, путём смешивания растворов органических веществ (концентрацию варьировали в интервале 3,4...100 мгО/л), выделенных из торфяных болот Томской области, и метасиликата натрия (в пересчете на кремний $20 \mathrm{мг/л).}$

Кремний в форме силикат-ионов и кремниевой кислоты определяли с использованием спектрофотометрического метода (фотометр КФК-3, Россия). Методика основана на взаимодействии кремниевой кислоты и силикатов с молибдатом аммония в кислой среде с образованием молибдокремниевой гетерополикислоты желтого цвета с максимумом поглощения при 410 нм [14]. Количественное определение силикат-ионов, связанных с гуминовыми веществами, проводили с использованием экстракции органо-минеральных комплексов хлороформом [15-17]. При этом примеси, связанные с гуминовыми веществами, переходят в ор- ганическую фазу. Долю силикат-ионов, связанных с гуминовыми веществами, рассчитывали по разности между содержанием кремния в растворе до и после экстракции.

Содержание гуминовых веществ определяли при помощи перманганатометрического титрования и выражали в единицах перманганатной окисляемости (ПО, мгО/л) [18]. Методика основана на окислении органических веществ, присутствующих в анализируемой пробе, перманганатом калия в сернокислой среде при нагревании с последующим добавлением щавелевой кислоты и титрованием её избытка перманганатом.

Определение ионов магния и кальция в воде и растворах проводили путем комплексонометрического титрования, в результате которого образуются окрашенные комплексы определяемых ионов с трилоном Б. Концентрацию ионов $\mathrm{Mg}^{2+}$ в растворах определяли по разности значений общей жесткости и концентрации ионов $\mathrm{Ca}^{2+}$.

Водородный показатель (pH) растворов контро-

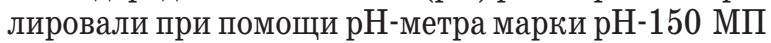
(Россия) с использованием стеклянного электрода. Характеристики частиц органо-минеральных коллоидов (распределение по размерам, Ц-потенциал) определяли при помощи анализатора Zetasizer Nano ZS (Великобритания). Фильтрование исследуемых растворов проводили с использованием бумажных фильтров «синяя лента» (диаметр пор $3 . .5$ мкм) и мембран «Millipore» (диаметр пор 400 и $1200 \mathrm{Hм})$.

\section{Результаты и их обсуждение}

Влияние соотношения исходных концентраций гумата и силиката натрия на содержание продуктов их взаимодействия - органо-минеральных комплексов - изучали с использованием модельных растворов. Доля $\mathrm{SiO}_{3}{ }^{2-}$-ионов, образующих органо-минеральные комплексы с ГВ, определяется соотношением ГВ: $\mathrm{SiO}_{3}{ }^{2-}$ и $\mathrm{pH}$ раствора. Из результатов анализа модельных растворов различного состава следует (табл. 1), что в интервале $\mathrm{pH}$ природной воды 5...9 определяющее значение в связывании ГВ и $\mathrm{SiO}_{3}{ }^{2-}$ представляет их соотношение. В интервале значений ПО растворов $4 . . .10 \mathrm{мгO} /$ л доля связанных $\mathrm{SiO}_{3}{ }^{2-}$-ионов практически не изменяется и составляет $20 . .22 \%$ от введенного количества, соотношение связанных компонентов ГВ: $\mathrm{SiO}_{3}{ }^{2-}$ в составе комплексов возрастает от 0,8 до 2,1 . Дальнейшее увеличение содержания ГВ в модельных смесях в 8 раз (ПО от 10 до 80 мгО/л) при постоянном начальном содержании $\mathrm{SiO}_{3}{ }^{2-}$ приводит к возрастанию доли связанных $\mathrm{SiO}_{3}{ }^{2-}$-ионов в два раза (до 40 \% ). При этом соотношение связанных в органо-минеральные комплексы реагентов ГВ: $\mathrm{SiO}_{3}{ }^{2-}$ достигает 4:1. Дальнейшее увеличение содержания гумата натрия в растворе не приводит к увеличению доли связанных силикат-ионов. Следовательно, до 40 \% кремния в природных высокоцветных водах (ПО до $30 \mathrm{MrO} /$ л) может находиться в составе органо-минеральных комплексов. 
Таблица 1. Влияние соотношения содержания силикат-ионов и гуминовых веществ в модельных растворах и рН на долю силикат-ионов, связанных в органо-минеральные комплексы

Table 1. Ratio of concentrations of silicate-ions and humic sub stances in the model solution and concentration of silicate ions combined with the humic substances

\begin{tabular}{|c|c|c|c|c|c|c|}
\hline \multicolumn{3}{|c|}{$\begin{array}{l}\text { Модельные растворы } \\
\text { Model solutions }\end{array}$} & \multicolumn{4}{|c|}{$\begin{array}{l}\text { Содержание силикат-ионов в растворе, мг/л } \\
\text { Silicon content in a solution, mg/L }\end{array}$} \\
\hline $\begin{array}{c}\mathrm{Si}, \\
\mathrm{Mг} / \text { л } \\
\mathrm{mg} / \mathrm{L}\end{array}$ & $\begin{array}{c}\text { ПО, } \\
\mathrm{MгO} / \text { л } \\
\mathrm{PO}, \\
\mathrm{mg} / \mathrm{L}\end{array}$ & $\mathrm{pH}$ & $\begin{array}{l}\text { До экстрак- } \\
\text { ции хлоро- } \\
\text { формом } \\
\text { Before ex- } \\
\text { traction }\end{array}$ & $\begin{array}{c}\text { После эк- } \\
\text { стракции } \\
\text { After ex- } \\
\text { traction }\end{array}$ & $\begin{array}{c}\text { Связан- } \\
\text { ный с ГВ } \\
\text { Combined } \\
\text { with the } \\
\text { HS }\end{array}$ & $\begin{array}{c}\text { Связанный } \\
\text { с ГВ, \% } \\
\text { Combined } \\
\text { with the } \\
\text { HS, } \%\end{array}$ \\
\hline \multirow{12}{*}{20,0} & 0,0 & 7,5 & 21,3 & 20,2 & 1,1 & 5 \\
\hline & 3,4 & 7,7 & 21,7 & 17,4 & 4,3 & 20 \\
\hline & 6,8 & 7,2 & 21,6 & 16,8 & 4,8 & 22 \\
\hline & 10,2 & 7,3 & 22,1 & 17,3 & 4,8 & 22 \\
\hline & 15,0 & 5,3 & 20,2 & 14,9 & 5,3 & 26 \\
\hline & 20,0 & 5,3 & 19,8 & 14,2 & 5,6 & 28 \\
\hline & 30,0 & 5,4 & 21,1 & 15,2 & 5,9 & 28 \\
\hline & 40,0 & 7,4 & 20,9 & 14,8 & 6,1 & 29 \\
\hline & 60,0 & 7,3 & 21,6 & 15,2 & 6,4 & 30 \\
\hline & 80,0 & 7,5 & 22,0 & 12,8 & 9,2 & 42 \\
\hline & 100,0 & 9,2 & 22,0 & 13,5 & 8,5 & 39 \\
\hline & 100,0 & 7,5 & 22,3 & 14,1 & 8,2 & 37 \\
\hline
\end{tabular}

Обозначения/Notes: По (РО) - перланганатная окисляелость (permanganate oxidizability), ГВ (HS) - гуминовые вещества ( $h u$ mic substances)

Состояние органо-минеральных коллоидных частиц, образующихся в модельных растворах в результате взаимодействия гумата и силиката натрия, исследовали с использованием метода динамического рассеяния света и электрокинетических измерений. В исследуемом диапазоне концентраций ГВ и $\mathrm{SiO}_{3}{ }^{2-}$ происходит образование коллоидных частиц, размеры и зарядовое состояние которых зависит от состава раствора (табл. 2). Увеличение соотношения ГВ: $\mathrm{SiO}_{3}{ }^{2-}$ от $1: 1$ до 4:1 приводит к увеличению среднего условного диаметра частиц дисперсной фазы в $\approx 3$ раза (от 68 до 195 нм). При этом происходит возрастание $\zeta$-потенциала от -50 до -38 мВ. Из сопоставления этих данных с данными табл. 1 следует, что высокое содержание органических веществ в воде в присутствии растворенных силикатов обусловливает образование органо-минеральных дисперсных систем, агрегативная устойчивость которых возрастает при увеличении доли кремния в них.

Таблица 2. Характеристики органо-минеральной дисперсной системы, форлирующейся при совместном присут ствии гумата и силиката натрия $\left(C_{S i}=20\right.$ мг/л) в модельных растворах $(\mathrm{pH}=7,4)$

Table 2. Characteristics of organo-mineral disperse system, which is formed in the joint presence of humate and sodi um silicate $\left(C_{S i}=20 \mathrm{mg} / L\right)$ in model solutions $(p H=7,4)$

\begin{tabular}{|l|c|c|c|c|}
\hline $\begin{array}{l}\text { Перманганатная окисляемость, мг0/л } \\
\text { Permanganate index, mg0/L }\end{array}$ & 20,0 & 40,0 & 60,0 & 80,0 \\
\hline $\begin{array}{l}\text { Средний условный диаметр частиц } \\
\text { дисперсной фазы, нм } \\
\text { Average particle size of the dispersed phase, nm }\end{array}$ & 68 & 82 & 167 & 195 \\
\hline $\begin{array}{l}\zeta \text {-потенциал, мB } \\
\zeta-\text { potential, mV }\end{array}$ & -50 & -48 & -45 & -38 \\
\hline
\end{tabular}

При соотношении ГВ: $\mathrm{SiO}_{3}{ }^{2-} \geq 3$ размеры коллоидных частиц значительно возрастают (табл. 2), что приводит к их коагуляции и снижению содержания кремния в растворе вследствие седиментации. Эффект формирования частиц дисперсной фазы может быть использован при разработке метода очистки высокоцветных природных вод от силикат-ионов.

Известно, что обескремнивание воды с применением реагентных методов очистки проводят в щелочной среде при $\mathrm{pH} \geq 10$ [8]. С учетом этого необходимо определить устойчивость органо-минеральных комплексов кремния в данной области pH. Щелочную среду в модельных растворах создавали путем введения различных реагентов (табл. 3). Из результатов анализа полученных растворов следует, что в щелочной среде комплексы ГВ с $\mathrm{SiO}_{3}{ }^{2-}$ неустойчивы, долей связанного с ГВ силикат-ионов можно пренебречь. Важным фактом является то, что присутствие ГВ в растворах не оказывает существенного влияния на осаждение дисперсной фазы с использованием соединений кальция и магния: снижение содержания силикат-ионов в растворе достигается за счет образования малорастворимых силикатов кальция и магния.

Таблииа 3. Содержание силикат-ионов в модельных системах при $\mathrm{pH}=10\left(\mathrm{C}_{\mathrm{Si}}=20 \mathrm{mг} / \mathrm{л} ; \Pi О=20 \mathrm{мг} / л ;\right.$ нагревание при $90^{\circ} \mathrm{C}$ в течение 10 мин)

Table 3. $\quad$ Content of dissolved forms of silicon in model systems at $\mathrm{pH}=10\left(\mathrm{C}_{\mathrm{Si}}=20 \mathrm{mg} / \mathrm{L} ; \mathrm{PO}=20 \mathrm{mg} / \mathrm{L}\right.$; heated at $90^{\circ} \mathrm{C}$ for $10 \mathrm{~min}$ )

\begin{tabular}{|c|c|c|}
\hline $\begin{array}{c}\text { Введенный реагент, } \\
20 \mathrm{мг} / л\end{array}$ & \multicolumn{2}{|c|}{$\begin{array}{c}\text { Содержание кремния, мг/л } \\
\text { Silicon content, mg/L }\end{array}$} \\
\cline { 2 - 3 } $\begin{array}{c}\text { Introduced reagent, } \\
20 \mathrm{mg} / \mathrm{L}\end{array}$ & $\begin{array}{c}\text { В отсутствие ГВ } \\
\text { With HS }\end{array}$ & $\begin{array}{c}\text { В присутствии ГВ } \\
\text { Without HS }\end{array}$ \\
\hline $\mathrm{NaOH}$ & 19,9 & 19,9 \\
\hline $\mathrm{Na}_{2} \mathrm{CO}_{3}$ & 19,9 & 19,9 \\
\hline $\mathrm{Ca}(\mathrm{OH})_{2}$ & 13,8 & 14,8 \\
\hline $\mathrm{MgO}$ & 9,5 & 10,2 \\
\hline
\end{tabular}

Обозначения/Notes: ПО (РО) - перланганатная окисляемость (permanganate oxidizability), ГВ (HS) - гуминовые вещества ( mic substances)

Для определения термодинамически устойчивых форм нерастворимых продуктов взаимодействия силикат-ионов с щелочными реагентами, образующихся в исследуемых системах (табл. 3), проведено моделирование кислотно-основных равновесий. Расчеты проведены с использованием программы «MINTEQ» [19], результаты представлены в виде диаграмм зависимости логарифма содержания растворимых и нерастворимых форм элементов от $\mathrm{pH}$ (рис. 1).

Анализ полученных диаграмм показал, что при совместном присутствии $0,001 \mathrm{M}$ силикат-ионов и катионов магния или кальция в широких интервалах концентраций и $\mathrm{pH}$ формируются устойчивые в среде растворов фазы, растворимость которых существенно ниже, чем растворимость кремниевой кислоты и соответствующих карбонатов (рис. 1): 

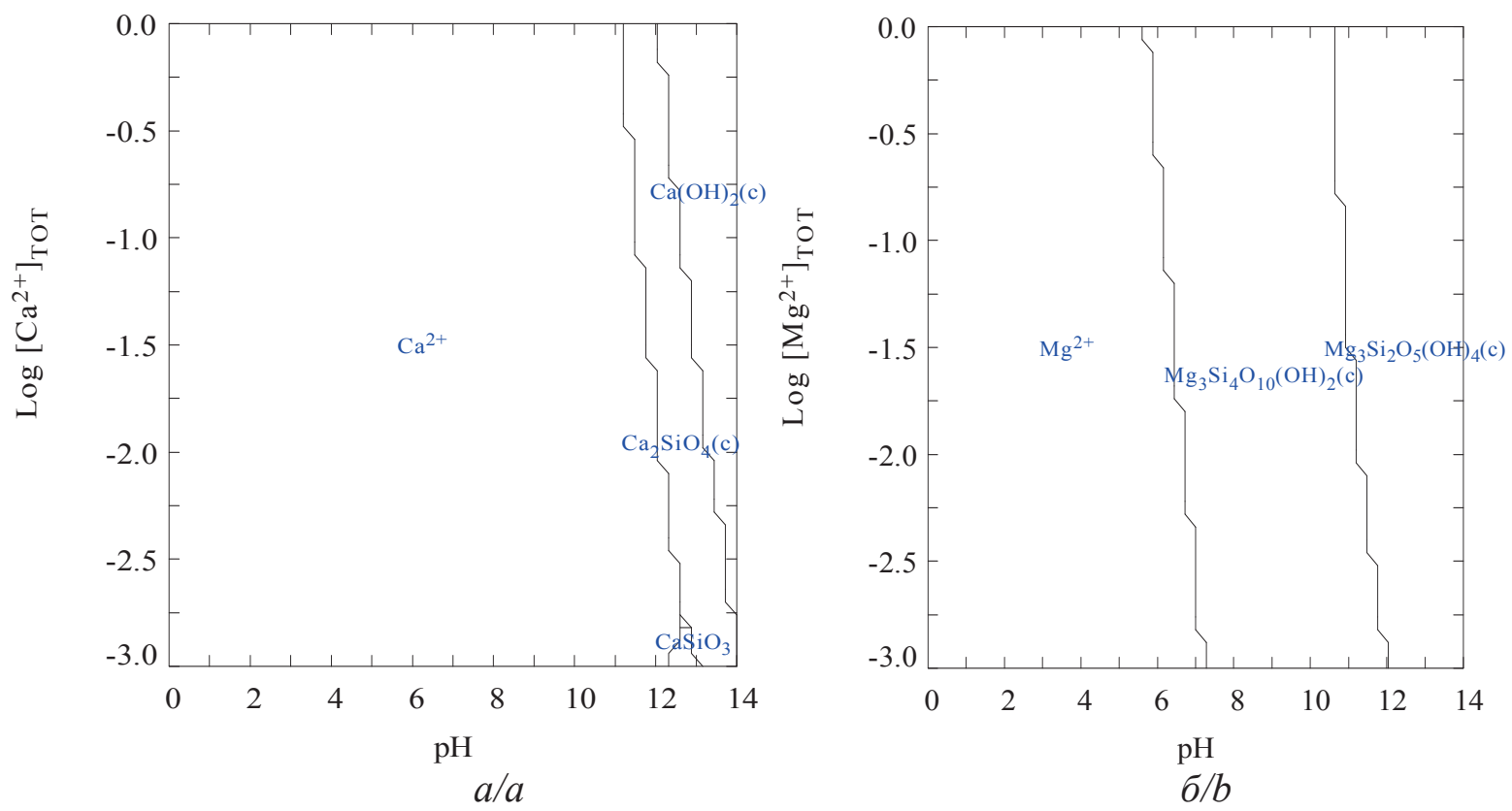

Pис. 1. Расчётные диаграмлы устойчивости равновесных форм в системах $\mathrm{Ca}^{2+}-\mathrm{SiO}_{3}{ }^{2-}-\mathrm{H}_{2} \mathrm{O}\left(\right.$ a) u $\mathrm{Mg}^{2+}-\mathrm{SiO}_{3}{ }^{2-}-\mathrm{H}_{2} \mathrm{O}$ (б) в зависимости om $\mathrm{pH}\left(\mathrm{C}_{0}\left(\mathrm{SiO}_{3}{ }^{2-}\right)=0,001 \mathrm{M} ; t=25^{\circ} \mathrm{C}\right)$

Fig. 1. Calculated diagrams of stability of equilibrium forms in the systems $\mathrm{Ca}^{2+}-\mathrm{SiO}_{3}{ }^{2-}-\mathrm{H}_{2} \mathrm{O}$ (a) $u \mathrm{Mg}^{2+}-\mathrm{SiO}_{3}{ }^{2-}-\mathrm{H}_{2} \mathrm{O}$ (b) depending on $\mathrm{pH}$ $\left(\mathrm{C}_{0}\left(\mathrm{SiO}_{3}{ }^{2-}\right)=0,001 \mathrm{M} ; t=25^{\circ} \mathrm{C}\right)$

$3 \mathrm{Mg}^{2+}+4 \mathrm{SiO}_{3}{ }^{2-}+2 \mathrm{H}_{2} \mathrm{O}=\mathrm{Mg}_{3} \mathrm{Si}_{4} \mathrm{O}_{10}(\mathrm{OH})_{2}+2 \mathrm{OH}^{-}, \mathrm{p} \Pi \mathrm{P}=21,4$; $3 \mathrm{Mg}^{2+}+2 \mathrm{SiO}_{3}{ }^{2-}+2 \mathrm{OH}^{-}+\mathrm{H}_{2} \mathrm{O}=\mathrm{Mg}_{3} \mathrm{Si}_{2} \mathrm{O}_{5}(\mathrm{OH})_{4}, \mathrm{p} \Pi \mathrm{P}=32,2$;

$$
\begin{aligned}
2 \mathrm{Ca}^{2+}+\mathrm{SiO}_{3}{ }^{2-}+2 \mathrm{OH}^{-} & =\mathrm{Ca}_{2} \mathrm{SiO}_{4}+\mathrm{H}_{2} \mathrm{O}, \mathrm{p} \Pi \mathrm{P}=37,6 ; \\
\mathrm{Ca}^{2+}+\mathrm{SiO}_{3}{ }^{2-} & =\mathrm{CaSiO}_{3}, \mathrm{p} \Pi \mathrm{P}=16,0 .
\end{aligned}
$$

Приведённые выше магнийсодержащие малорастворимые соединения широко распространены в земной коре в виде минералов со слоистой структурой (хризотилы $\mathrm{Mg}_{3} \mathrm{Si}_{2} \mathrm{O}_{5}(\mathrm{OH})_{4}$, тальк $\left.\mathrm{Mg}_{3} \mathrm{Si}_{4} \mathrm{O}_{10}(\mathrm{OH})_{2}\right)$. В отличие от основных полисиликатов магния, си- ликаты кальция (мета- и орто-силикат) устойчивы в сильнощелочной среде, а в нейтральных раствоpax быстро гидролизуются. В соответствии с диаграммами состав соединений магния определяется $\mathrm{pH}$ раствора в большей степени, чем соотношением концентраций исходных реагентов. При этом в интервале $\mathrm{pH}=7 . . .11$ формируется малорастворимый продукт с большей долей силикат-ионов, чем в сильнощелочной среде (рис. 1). Следовательно,

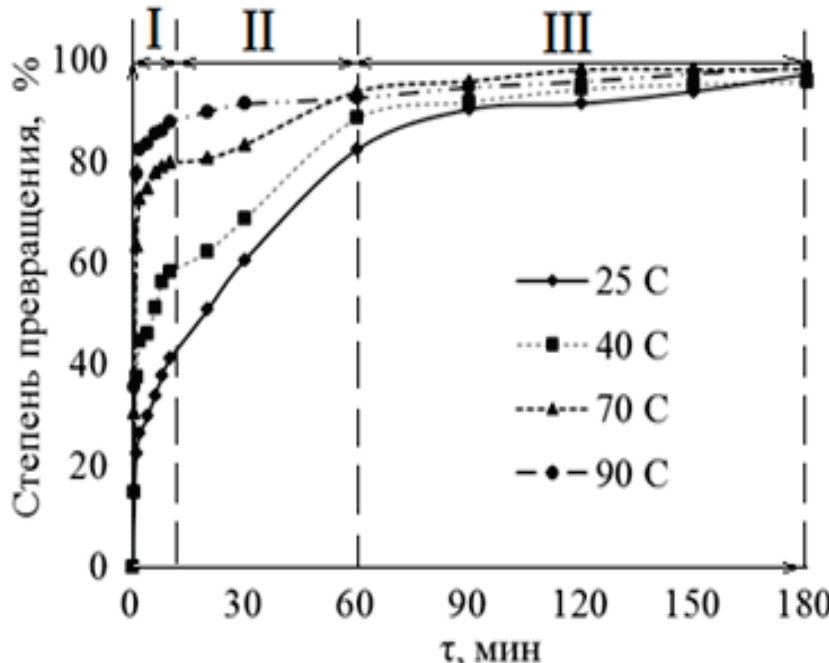

$a / a$

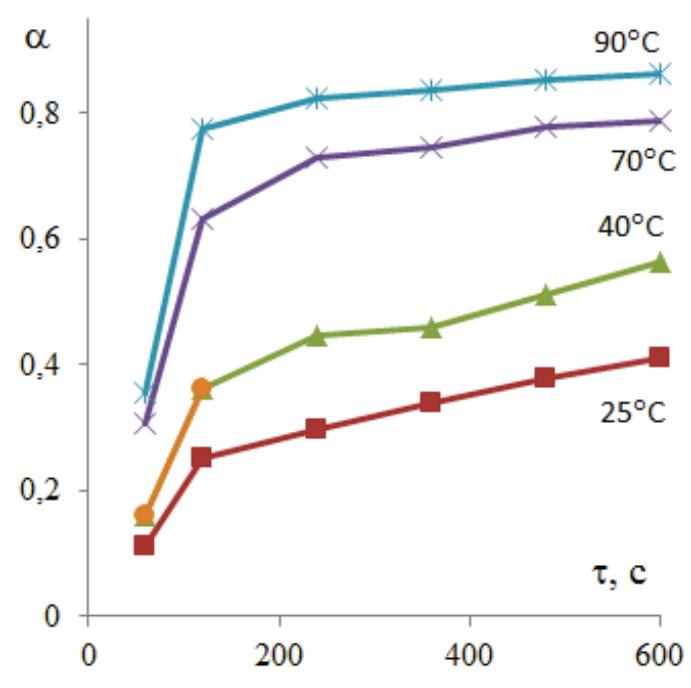

$6 / b$

Pис. 2. Зависимость степени превращения $\mathrm{SiO}_{3}{ }^{2-}{ }^{-}$ионов от врелени взаилодействия с частицами каустического магнезита при различных телпературах

Fig. 2. Dependence of the degree of transformation of $\mathrm{SiO}_{3}{ }^{2-}$ ions on the time of interaction with particles of caustic magnesite at various temperatures 
создание слабощелочной среды при магнезиальном обескремнивании воды позволит более эффективно использовать реагент-осадитель и достигать больших степеней очистки от силикат-ионов, чем при $\mathrm{pH}>11$.

Влияние присутствия в системе гуминовых веществ на скорость взаимодействия силикат-ионов с каустическим магнезитом изучали в интервале $25 . . .90{ }^{\circ} \mathrm{C}$. Реакция между частицами взвеси $\mathrm{MgO}$ и $\mathrm{SiO}_{3}{ }^{2-}$-ионами является гетерогенной и протекает на поверхности частиц каустического магнезита с образованием слоя нерастворимых продуктов. На рис. 2 приведены зависимости степени превращения от времени протекания реакции, рассчитанные по значениям текущих концентраций силикат-ионов в реакционной смеси при различных температурах.

Удаления силикат-ионов из реакционной смеси в зависимости от продолжительности взаимодействия протекает в три этапа (рис. $2, a)$ :

- I - активное протекание реакции (10 мин);

- II - замедление реакции (10...60 мин);

- III - окончание реакции (более 60 мин).

Из анализа начальных участков зависимостей $\alpha=f(\tau)$ (рис. 2, б) следует, что скорость взаимодействия силикат-ионов с оксидом магния с течением времени изменяется немонотонно. При продолжительности заимодействия $\approx 120$ с степень превращения возрастает скачкообразно во всем интервале температур, далее изменение величины $\alpha$ протекает медленно. Максимальное снижение концентрации $\mathrm{SiO}_{3}{ }^{2-}$-ионов в растворе в начальный период происходит при нагревании $\left(t \geq 70{ }^{\circ} \mathrm{C}\right)$, при более низких температурах значения $\alpha<50 \%$. Анализ зависимостей в логарифмических координатах $\ln \alpha=f(\lg \tau)$ показал, что скорость реакции по $\mathrm{SiO}_{3}{ }^{2-}$-ионам при продолжительности процесса $\tau \leq 120$ с удовлетворительно описывается уравнением 1-го порядка:

$$
\alpha=1-\exp \left(-k_{\text {эф }} \tau\right)
$$

где $\alpha$ - степень превращения; $k_{\text {эф }}$ - эффективная константа скорости; $\tau$ - время. Путем линеаризации экспериментальных данных в координатах ln $[1 /(1-\alpha)]=f(\tau)$ для начальных участков зависимостей степени превращения от времени при $\tau \leq 120$ с были определены эффективные значения константы скорости реакции при различных температурах (табл. 4).

Таблица 4. Эффективные константы скорости взаимодействия силикат-ионов с частицали каустического магнезита на начальной стадии ( $\tau \leq 120$ с) при раз личных температурах

Table 4. Effective rate constants of interaction of silicate ions with particles of caustic magnesite at the initial stage $(\tau \leq 120 \mathrm{~s})$ at various temperatures

\begin{tabular}{|c|c|c|c|}
\hline$t,{ }^{\circ} \mathrm{C}$ & $1 / T, \mathrm{~K}^{-1}$ & $k_{\text {э中 }}, \mathrm{c}^{-1}$ & $\ln k_{\text {э中 }}$ \\
\hline 25 & 0,00336 & 0,0030 & $-5,8091$ \\
\hline 40 & 0,00319 & 0,0045 & $-5,4037$ \\
\hline 70 & 0,00292 & 0,0106 & $-4,5469$ \\
\hline 90 & 0,00275 & 0,0175 & $-4,0456$ \\
\hline
\end{tabular}

При увеличении продолжительности взаимодействия $\tau>120$ с порядок реакции по $\mathrm{SiO}_{3}{ }^{2-}$-ионам существенно снижается до $0,1 . . .0,3$. При этом степени превращения выходят на насыщение (рис. 2, б).

Из полученных данных следует, что реакционная поверхность частиц каустического магнезита быстро блокируется слоем нерастворимых силикатов магния, который играет роль диффузионного барьера и приводит к снижению скорости удаления кремния из раствора в течение II и III периодов протекания реакции (рис. $2, a$ ).

Эффективную энергию активации $E_{\text {a }}$ процесса на начальной стадии ( $\tau \leq 120$ c) определяли графически по зависимостям логарифма эффективной константы скорости уменьшения концентрации $\mathrm{SiO}_{3}{ }^{2-}$-ионов от обратной температуры (табл. 4). График зависимости $\ln k_{\text {эф }}=f(1 / T)$ является линейным в исследуемом интервале температур, среднее

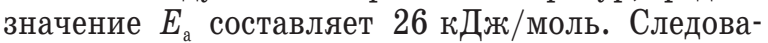
тельно, в начальный период взаимодействие силикат-ионов с поверхностью частиц каустического магнезита протекает быстро, замедленной стадией является диффузия реагентов к реакционной поверхности. В результате реакции образуются нерастворимые силикаты магния, слой которых блокирует поверхность частиц каустического магнезита и замедляет процесс. Существенное возрастание величины $\alpha$ для 1-го и 2-го периодов процесса при нагревании происходит в связи с повышением растворимости $\mathrm{MgO}$ в этих условиях [20], что приводит к повышению концентрации ионов магния в приповерхностном слое частиц каустического магнезита и возрастанию скорости взаимодействия с силикат-ионами.

\section{Выводы}

1. С использованием модельных растворов, содержащих силикат и гумат натрия в концентрациях, близких к содержанию ионов кремния и гуминовых веществ в природных водах, определен интервал соотношений (мг/л) ГВ: $\mathrm{SiO}_{3}{ }^{2-}=0,8 \ldots 4$, в котором ГВ и $\mathrm{SiO}_{3}{ }^{2-}$-ионы при совместном присутствии в интервале $\mathrm{pH}=5 . . .9$ связываются в органо-минеральные комплексы. Показано, что в природных высокоцветных водах (величина ПО до 30 мгО/л) до 40 \% силикат-ионов входит в состав таких комплексов, что вызывает сложности в процессах водоподготовки.

2. Кремнийсодержащие органо-минеральные комплексы в воде и растворах способствуют формированию дисперсной фазы, размеры и заряд частиц которой определяется соотношением ГВ: $\mathrm{SiO}_{3}{ }^{2-}$. Увеличение этого соотношения в интервале $1 . . .4$ при $\mathrm{pH} \approx 7$ обусловливает увеличение среднего условного диаметра коллоидных частиц от 68 до 195 нм и возрастание $\zeta$-потенциала от -50 до -38 мВ, что выражается в снижении агрегативной устойчивости такой дисперсной системы. 
3. По результатам моделирования кислотно-основных равновесий в системах $\mathrm{Ca}^{2+}-\mathrm{SiO}_{3}{ }^{2-}-\mathrm{H}_{2} \mathrm{O}$ и $\mathrm{Mg}^{2+}-\mathrm{SiO}_{3}{ }^{2-}-\mathrm{H}_{2} \mathrm{O}$ показано, что наименее растворимыми термодинамически устойчивыми фазами в области $\mathrm{pH}>7$ являются основные полисиликаты магния $\mathrm{Mg}_{3} \mathrm{Si}_{2} \mathrm{O}_{5}(\mathrm{OH})_{4}$ и $\mathrm{Mg}_{3} \mathrm{Si}_{4} \mathrm{O}_{10}(\mathrm{OH})_{2}$. В отличие от них, малорастворимые мета- и ортосиликат кальция образуются в сильнощелочной среде $(\mathrm{pH}>12)$.

4. По результатам изучения скорости взаимодействия частиц каустического магнезита с сили-

\section{СПИСОК ЛИТЕРАТУРЫ}

1. Iron oxidation in different types of groundwater of Western Siberia / L.V. Serikov, E.A. Tropina, L.N. Shiyan, F.H. Frimmel, G. Metreveli, M. Delay // Journal for Soils and Sediments. 2009. - № 2. - P. 103-110.

2. Konchakova N.V., Ushakova N.S., Aikina T.Yu. Ecological risk assessment of Tomsk region groundwater used for drinking purposes // IOP Conference Series: Earth and Environmental Science. - 2016. - V. 33. - P. 012022(1-6).

3. Colloid Stability of Iron Compounds in Groundwater of Western Siberia / L.N. Shiyan, E.A. Tropina, K.I. Machekhina, E.N. Gryaznova, V.V. An. - 2014. - V. 3:260. D0I: 10.1186/2193-1801-3-260, http://www.springerplus.com/content/3/1/260.

4. Санитарные правила и нормы СанПиН 2.1.4.1074-01. Питьевая вода. Гигиенические требования к качеству воды централизованных систем водоснабжения. Контроль качества. Санитарно-эпидемиологические правила и нормативы. - М.: Федеральный центр Госсанэпиднадзора Минздрава России, 2002. $103 \mathrm{c.}$

5. Стерман Л.С., Покровский В.Н. Физические и химические методы обработки воды на ТЭС. - М.: Энергоатомиздат, 1991. $328 \mathrm{c.}$

6. Chan S.H. A review on solubility and polymerization of silica // Geothermics. - 1989. - V. 18. - № 1/2. - P. 49-56.

7. Исследование интенсифицированной коагуляционной очистки воды с использованием микропеска / Б.Е. Рябчиков, С.Ю. Ларионов, А.А. Пантелеев, М.М. Шилов // Водоснабжение и санитарная техника. - 2015. - № 5. - С. 14-21.

8. Жадан А.В. Совершенствование технологии обработки воды на ТЭС на базе ионного обмена и мембранных методов: дис.... канд. тех. наук. - Иваново, 2013. - 193 с.

9. Raschman P., Fedorocková A. Study of Inhibiting Effect of Acid Concentration on the Dissolution Rate of Magnesium 0xide during the Leaching of Dead-burned Magnesite // Hydrometallurgy. - 2004. - V. 71. - P. 403-412.

10. Den W., Wang C.-J. Removal of silica from brackish water by electrocoagulation pretreatment to prevent fouling of reverse os- кат-ионами в перемешиваемой суспензии в присутствии ГВ показано, что начальные участки зависимостей степени превращения от времени ( $\tau \leq 120$ с) описываются уравнением 1-го порядка, определены эффективные константы скорости реакции. Для интервала температур $25 . . .90{ }^{\circ} \mathrm{C}$ определена эффективная энергия активации, равная 26 кДж/моль, что свидетельствует о диффузионном контроле процесса.

mosis membranes // Separation and Purification Technology. 2008. - V. 59. - № 1.3. - P. 318-325.

11. Семенова И.В., Тимофеев М.В., Хорошилов А.В. Изучение состава и структуры осадков, образующихся при обработке воды щелочью и щелочным реагентом Гидро-Икс (HYDRO-X) // Энергосбережение и водоподготовка. - 2003. - № 4. - С. 25-28.

12. Способ приготовления модельного коллоидного раствора: пат. Рос. Федерация № 2502556, заявл. 12.07.2012, опубл. 27.12.2013, Бюл. № 11. - 5 с.

13. ГОСТ 6709-72. Вода дистиллированная. Технические условия. - Взамен ГОСТ 6709-53; Введ. 01.01.74. - М.: Изд-во стандартов, 1997. - 7 с.

14. РД 52.24.433-2005. Массовая концентрация кремния в поверхностных водах суши. Методика выполнения измерений фотометрическим методом в виде желтой формы молибдокремниевой кислоты. Введ. 01.07.2005. - М.: Росгидромет, 2005. -28 c.

15. Барс Е.А., Коган С.С. Методическое руководство по исследованию органических веществ подземных вод нефтегазоносных областей. - М.: Недра, 1979. - 156 с.

16. Humic acid desorption from a positively charged nanocellulose surface / H. Sehaqui, L. Schaufelberger, B. Michen, T. Zimmermann // J. Coll. Int. Sci. - 2017. - № 504. - P. 500-506.

17. Способ определения концентрации кремния в воде: пат. Рос. Федерация № 2656121, заявл. 10.01.2017, опубл. 31.05.2018, Бюл. № 16. -3 c.

18. ГОСТ Р 55684-2013. Вода питьевая. Метод определения перманганатной окисляемости. Введ. 31.10.2013. - М.: Стандартинформ, 2014. - 27 с.

19. Felmy A., Girvin D., Jenne E. MINTEQ: A computer program for calculating aqueous geochemical equilibria. - Washington: US Environmental Protection Agency, 1984. - 98 p.

20. Рабинович В.А., Хавин 3.Я. Краткий химический справочник. - Л.: Химия, 1991. - 432 с.

Поступила 15.01.2019 2.

\section{Информация об авторах}

Костикова Л.А., инженер-проектировщик Центра коллективного пользования «Физико-химические методы анализа» Национального исследовательского Томского политехнического университета.

Шиян Л.H., кандидат физико-математических наук, доцент отделения естественных наук Школы базовой инженерной подготовки Национального исследовательского Томского политехнического университета.

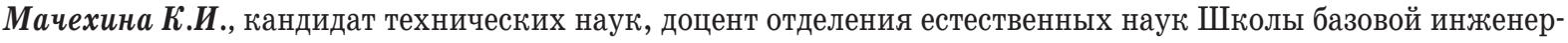
ной подготовки Национального исследовательского Томского политехнического университета.

Kоршунов A.B., доктор химических наук, профессор отделения естественных наук Школы базовой инженерной подготовки Национального исследовательского Томского политехнического университета. 


\title{
CONDITIONS OF COMBINED SEDIMENTATION OF SILICON AND HUMIC SUBSTANCES FROM NATURAL WATERS IN THE PRESENCE OF CAUSTIC MAGNESITE
}

\author{
Larisa A. Kostikova', \\ lak@tpu.ru \\ Lyudmila N. Shiyan', \\ shln@tpu.ru \\ Ksenia I. Machekhina', \\ mauthksu@yandex.ru \\ Andrey V. Korshunov', \\ korshunov@tpu.ru \\ 1 National Research Tomsk Polytechnic University, \\ 30, Lenin avenue, Tomsk, 634050, Russia.
}

The relevance. Ground sources of drinking water supply in the West Siberian region are characterized by high content of iron ions, silicate ions and organic substances of humus origin. These impurities lead to formation of a stable colloidal system. When using water as a cooler and in heating systems, silicate deposits are formed on the surface of the pipes, due to the ability of silicic acid to form insoluble compounds with calcium and magnesium cations, as well as with aluminum, iron and sodium cations. The combined presence of silicates and organic impurities reduces the effectiveness of existing water purification technologies.

The aim of the research is to study the conditions of formation of silicon compounds with humic substances and the kinetics of interaction with caustic magnesite.

Objects of research are natural waters and model solutions containing silicon compounds and dissolved humic substances, natural caustic magnesite.

Methods: photocolorimeter, pH-meter, titrometry, inductively coupled plasma atomic emission spectrometry (ICAP-6000).

Results. The authors have established the concentration ratio of silicate ions/humic substances in which colloidal particles are formed at concentrations of silicate ions $20 \mathrm{mg} / \mathrm{L}$ and humic substances $80 \mathrm{mg} / \mathrm{L}$ at pH=5...9. The size of the resulting colloidal particles is $200 \mathrm{~nm}$, and the value of $\zeta$-potential is $-38 \mathrm{mV}$. It is shown that in the range of $\mathrm{pH}$ values from 7,0 to 10 the colloidal compounds are stable. When using caustic magnesite as a precipitant reagent, the interaction in the "silicate-humic substances" system proceeds in two stages, which determine the technological feasibility of simultaneous removal of silicates and humic substances from water.

\section{Key words:}

Natural water, silicon compounds, organic-mineral substances, particle size, water purification, caustic magnesite.

\section{REFERENCES}

1. Serikov L.V., Tropina E.A., Shiyan L.N., Frimmel F.H., Metreveli G., Delay M., Iron oxidation in different types of groundwater of Western Siberia. Journal for Soils and Sediments, 2009, no. 2, pp. $103-110$.

2. Konchakova N.V., Ushakova N.S., Aikina T.Yu. Ecological risk assessment of Tomsk region groundwater used for drinking purposes. IOP Conference Series: Earth and Environmental Science, 2016, vol. 33, pp. 012022 (1-6).

3. Shiyan L.N., Tropina E.A., Machekhina K.I., Gryaznova E.N., An V.V. Colloid Stability of Iron Compounds in Groundwater of Western Siberia. 2014, vol. 3. DOI: 10.1186/2193-1801-3-260, http://www.springerplus.com/content/3/1/260.

4. Sanitarnie pravila i normy SanPin 2.1.4.1074-01. Pitievaya voda. Gigienicheskiye trebovaniya $k$ kachestvu vodi tsentralizovannykh sistem vodosnabzheniya. Kontrol kachestva. Sanitarno-epidemiologicheskie pravila i normativy [Sanitary rules and regulations SanPiN 2.1.4.1074-01. Drinking water. Hygienic requirements for water quality of centralized water supply systems. Quality control. The sanitary and epidemiological rules and norms]. Moscow, Federal Centre for Sanitary Inspection Ministry of Health of Russia, $2002.103 \mathrm{p}$.

5. Sterman L.S., Pokrovskiy V.N. Fizicheskie $i$ khimicheskie metody obrabotki vody na TES [Physical and chemical methods of water treatment at TPPs]. Moscow, Energoatomizdat Publ., 1991. $328 \mathrm{p}$.
6. Chan S.H. A review on solubility and polymerization of silica. Geothermics, 1989, vol. 18, no. 1/2, pp. 49-56.

7. Ryabchikov B.E., Larionov S.Yu., Panteleev A.A., Shilov M.M. Issledovanie intensifitsirovannoy koagulyatsionnoy ochistki vody s ispolzovaniem mikropeska [Investigation of intensified coagulation water purification using microsand]. Water supply and sanitary equipment, 2015, no. 5, pp. 14 ?21.

8. Zhadan A.V. Sovershenstvovanie tekhnologii obrabotki vody na TES na baze ionnogo obmena i membrannykh metodov. Dis. Kand. nauk [Improvement of water treatment technology at TPPs based on ion exchange and membrane methods. Cand. Diss.]. Ivanovo, 2013. $193 \mathrm{p}$.

9. Raschman P.l., Fedorocková A. Study of Inhibiting Effect of Acid Concentration on the Dissolution Rate of Magnesium Oxide during the Leaching of Dead-burned Magnesite. Hydrometallurgy, 2004, vol. 71, pp. 403-412.

10. Den W., Wang C.-J. Removal of silica from brackish water by electrocoagulation pretreatment to prevent fouling of reverse osmosis membranes. Separation and Purification Technology, vol. 59 , pp. 318-325.

11. Semenova I.V., Timofeev M.V., Khoroshilov A.V. Izuchenie sostava i struktury osadkov obrazuyushchikhsya pri obrabotke vody shchelochyu $i$ shchelochnym reagentom gidro iks (HYDRO-X) [Study of composition and structure of sediments formed during water treatment with alkali and with the alkaline reagent HydroX]. Energy Saving and Water Treatment, 2003, no. 4, pp. 25-28. 
12. Shiyan L.N., Tropina E.A., Machekhina K.I., Grayznova E.N., Vlasov V.A. Sposob prigotouleniya modelnogo kolloidnogo rastvo$\mathrm{ra}$ [A method of preparation of the model colloidal solution]. Patent RF, no. 2502556, 2013.

13. GOST 6709-72. Voda distillirovannaya. Tekhnicheskie usloviya. Vzamen GOST 6409-53; Vved.01.01.74 [State Standard 6709-72. Distilled water. Technical conditions. Instead of the State Standard 6709-53; Introduced 01.01.74]. Moscow, Publ. House of Standards, $1997.7 \mathrm{p}$.

14. Rukovodyashchiy document 52.24.433-2005. Massovaya kontsentratsiya kremniya v poverkhnostnykh vodakh sushi. Metodika vypolneniya izmereniy fotometricheskim metodom v vide zheltoy for my molibdokremniyevoy kisloty. Vved. 01.07.2005 [Management directive 52.24.433-2005. Mass concentration of silicon in surface natural waters. A methodical aid for photometric measurements in the vellow form of molybdosilicic acid. Introduced 01.07.2005]. Moscow, Rosgidromet Publ., 2005. 28 p.

15. Bars E.A., Kogan S.S. Metodicheskoe rukovodstvo po issledovaniyu organicheskikh veshchestv podzemnykh vod neftegazonosnykh oblastey [Methodological guide to the study of organic matter in groundwater oil and gas regions]. Moscow, Nedra Publ., 1979. $156 \mathrm{p}$.

\section{Information about the authors}

Larisa A. Kostikova, engineer-designer, National Research Tomsk Polytechnic University.

Lyudmila N. Shiyan, Cand. Sc., associate professor, National Research Tomsk Polytechnic University.

Ksenia I. Machekhina, Cand. Sc., associate professor, National Research Tomsk Polytechnic University.

Andrey V. Korshunov, Dr. Sc., professor, National Research Tomsk Polytechnic University.
16. Sehaqui H., Schaufelberger L., Michen B., Zimmermann T. Humic acid desorption from a positively charged nanocellulose surface. J.Coll. Int. Sci., 2017, no. 504, pp. 500-506.

17. Shiyan L.N., Machekhina K.I., Kostikova L.A. Sposob opredelenia koncentracii kremniya $v$ vode [A method for determination of silicon concentration in water]. Patent RF, no. 2656121, 2018.

18. GOST R 55684-2013. Voda pitievaya. Metod opredeleniya permanganatnoy okislyayemosti.Vved. 31.10.2013 [State Standard R 55684-2013. Drinking water. Methods of determination of permanganate oxidizability. Introduced 31.10.2013]. Moscow, Standartinform Publ., 2014. 27 p.

19. Felmy A., Girvin D., Jenne E. MINTEQ: a computer program for calculating aqueous geochemical equilibria. Washington, US Environmental Protection Agency, 1984. 98 p.

20. Rabinovich V.A., Khavin Z.I. Kratkiy khimicheskiy spravochnik [Brief Chemical Reference]. Leningrad, Khimiya Publ., 1991. $432 \mathrm{p}$.

Received: 15 January 2019. 